\title{
North American Monsoon and Convectively Coupled Equatorial Waves Simulated by IPCC AR4 Coupled GCMs
}

\author{
JIA-LIN LIN \\ NOAA/ESRL, and CIRES Climate Diagnostics Center, Boulder, Colorado, and Department of Geography, \\ The Ohio State University, Columbus, Ohio \\ BRIAN E. MAPES \\ RSMAS, University of Miami, Miami, Florida \\ Klaus M. Weickmann and George N. Kiladis \\ NOAA/ESRL, and CIRES Climate Diagnostics Center, Boulder, Colorado \\ Siegfried D. SChubert AND MAX J. SuARez \\ Global Modeling and Assimilation Office, NASA/GSFC, Greenbelt, Maryland \\ Julio T. BACMEISTER AND Myong-In LeE \\ Global Modeling and Assimilation Office, NASA/GSFC, Greenbelt, and Goddard Earth Sciences and Technology Center, \\ University of Maryland, Baltimore County, Baltimore, Maryland
}

(Manuscript received 14 December 2006, in final form 16 November 2007)

\begin{abstract}
This study evaluates the fidelity of North American monsoon and associated intraseasonal variability in the Intergovernmental Panel on Climate Change (IPCC) Fourth Assessment Report (AR4) coupled general circulation models (CGCMs). Twenty years of monthly precipitation data from each of the 22 models' twentieth-century climate simulations, together with the available daily precipitation data from 12 of them, are analyzed and compared with Global Precipitation Climatology Project (GPCP) monthly and daily precipitation. The authors focus on the seasonal cycle and horizontal pattern of monsoon precipitation in conjunction with the two dominant convectively coupled equatorial wave modes: the eastward-propagating Madden-Julian oscillation (MJO) and the westward-propagating easterly waves.

The results show that the IPCC AR4 CGCMs have significant problems and display a wide range of skill in simulating the North American monsoon and associated intraseasonal variability. Most of the models reproduce the monsoon rainbelt, extending from southeast to northwest, and its gradual northward shift in early summer, but overestimate the precipitation over the core monsoon region throughout the seasonal cycle and fail to reproduce the monsoon retreat in the fall. Additionally, most models simulate good westward propagation of the easterly waves, but relatively poor eastward propagation of the MJO and overly weak variances for both the easterly waves and the MJO. There is a tendency for models without undiluted updrafts in their deep convection scheme to produce better MJO propagation.
\end{abstract}

\section{Introduction}

The North American monsoon, also known as the southwest U.S. monsoon, the Mexican monsoon, or the Arizona monsoon, significantly affects the precipitation

Corresponding author address: Dr. Jia-Lin Lin, Department of Geography, The Ohio State University, 1105 Derby Hall, 154 North Oval Mall, Columbus, OH 43210.

E-mail: lin.789@osu.edu and large-scale circulation over much of the western United States and northwestern Mexico (Douglas et al. 1993; Higgins et al. 1997; Adams and Comrie 1997; Barlow et al. 1998; Higgins and Shi 2001; see schematic in Fig. 1) and has stimulated strong interest in the prediction and research communities, leading to the recent North American Monsoon Experiment (NAME; Higgins and NAME Science Working Group 2003; Higgins et al. 2006; Vera et al. 2006). The North American monsoon also has strong intraseasonal variability with two 


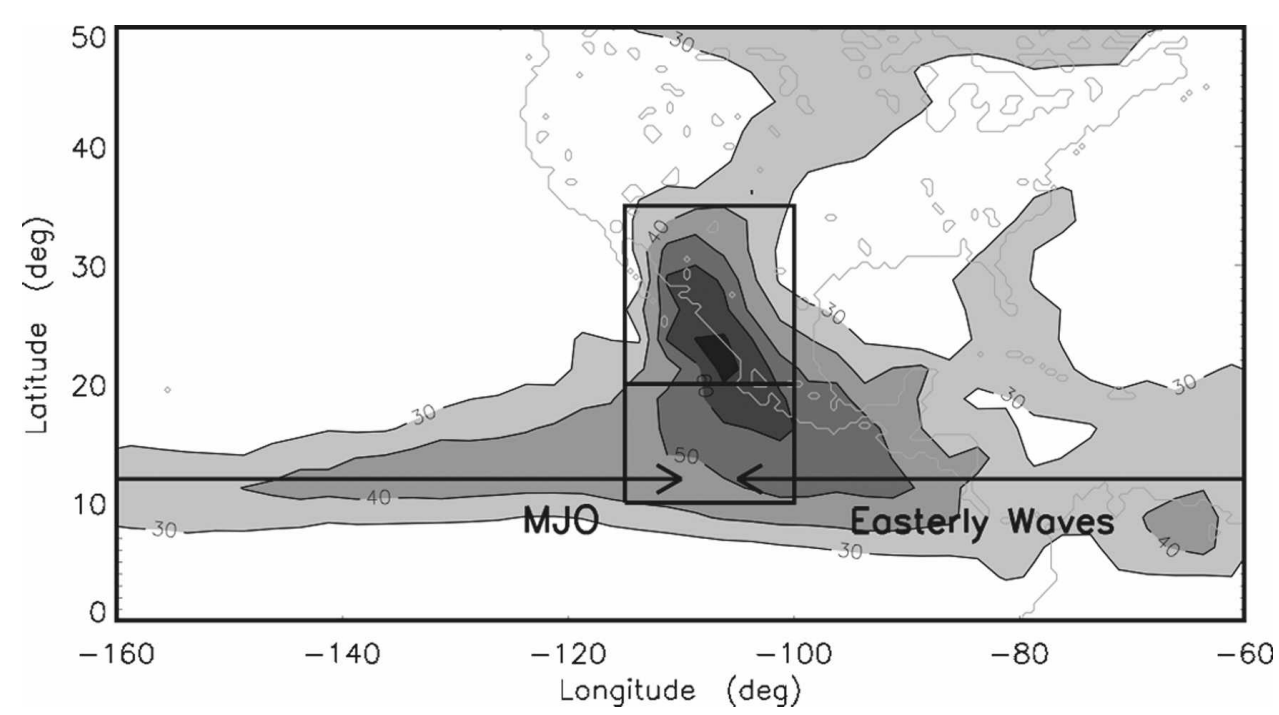

FIG. 1. Schematic depiction of the North American monsoon and its two dominant convectively coupled equatorial wave modes: MJO and easterly waves. Contour denotes the percentage of annual mean GPCP precipitation that falls in the monsoon season (July-September). The two boxes denote the regions with the largest seasonal variation, with the northern box being the core monsoon region.

dominant modes: the Madden-Julian oscillation (MJO) that propagates eastward from the western and central Pacific (Higgins and Shi 2001; Lorenz and Hartmann 2006) and easterly waves that propagate westward from the Atlantic Ocean (e.g., Lau and Lau 1990; Avila 1991; Avila and Pasch 1992; Molinari et al. 1997; Raymond et al. 1998; Zehnder et al. 1999; Molinari et al. 2000; Fuller and Stensrud 2000; Serra and Houze 2002; Petersen et al. 2003; Adams and Stensrud 2007). Both of these modes significantly modulate the monsoon precipitation and the formation, intensity, and track of the tropical cyclones and are therefore important for both weather and climate prediction.

Many previous studies have used high-resolution regional models to simulate the North American monsoon and associated intraseasonal variability, and there have been significant improvements from the earlier simulations to more recent studies (e.g., Giorgi 1991; Dunn and Horel 1994; Anderson et al. 2000; Gochis et al. 2002; Mo and Juang 2003). Currently there is a comprehensive multimodel assessment project associated with NAME (Gutzler et al. 2005). For the general circulation models (GCMs), on the other hand, only a few previous studies have examined the simulations of the North American monsoon and associated intraseasonal variability by individual models (e.g., Krishnamurti et al. 2000; Arritt et al. 2000; Yang et al. 2001; Berbery and Fox-Rabinovitz 2003; Kunkel 2003; Farrara and Yu 2003; Collier and Zhang 2006; Lee et al. 2007). The success of these simulations is sensitive to a variety of factors, such as horizontal resolution (Berbery and Fox-
Rabinovitz 2003; Lee et al. 2007), boundary conditions (Yang et al. 2001), and convective parameterization (Collier and Zhang 2006). However, to our knowledge, no multimodel intercomparison has been conducted to evaluate the general status of the simulations of the North American monsoon and associated intraseasonal variability in the GCMs.

Recently, in preparation for the Intergovernmental Panel on Climate Change (IPCC) Fourth Assessment Report (AR4), more than 20 international climate modeling centers conducted a comprehensive set of long-term simulations both for twentieth-century climate and for different climate change scenarios in the twenty-first century. Before conducting the extended simulations, many of the modeling centers updated their physical schemes to incorporate recent research results. Many model intercomparison studies have evaluated the dominant tropical modes simulated by the IPCC AR4 coupled general circulation models (CGCMs), such as the annual mean ITCZ (Lin 2007), ENSO (AchutaRao and Sperber 2006; Capotondi et al. 2006; Joseph and Nigam 2006), the MJO, and convectively coupled equatorial waves (Lin et al. 2006). For example, Lin et al. (2006) evaluated the all-season behavior of the MJO and convectively coupled equatorial waves in 14 models. They found that about half of the models have signals of convectively coupled equatorial waves, with especially prominent Kelvin and mixed Rossby-gravity (MRG)-eastward inertio-gravity (EIG) waves. However, the variances are generally too weak for all wave modes except the EIG wave, and the phase 
speeds are generally too fast, being scaled to excessively deep equivalent depths, which suggests that these models may not have a large enough reduction in their "effective static stability" by diabatic heating. The MJO variance approaches the observed value in only 2 of the 14 models, but is less than half of the observed value in the other 12 models. The ratio between the eastward MJO variance and the variance of its westward counterpart is too small in most of the models, which is consistent with the lack of highly coherent eastward propagation of the MJO in many models. Moreover, the MJO variance in 13 of the 14 models does not come from a pronounced spectral peak; rather, it usually comes from part of an overreddened spectrum, which in turn is associated with too-strong persistence of equatorial precipitation. The two models that arguably do best at simulating the MJO are the only ones with convective closures/triggers linked in some way to moisture convergence.

The purpose of this study is to extend the Lin et al. (2006) study to evaluate the North American monsoon and associated intraseasonal variability in the IPCC models. The questions we address are as follows:

1) How well do the models simulate the North American monsoon?

2) How well do the models simulate the intraseasonal precipitation signals associated with the North American monsoon, especially the MJO and tropical easterly waves?

3) Is there any systematic dependence of model simulations on the basic characteristics of convection schemes, such as their cloud models or closure assumptions?

The models and validation datasets used in this study are described in section 2 . The diagnostic methods are described in section 3. Results are presented in section 4. A summary and discussion are given in section 5 .

\section{Models and validation datasets}

This analysis is based on $21 \mathrm{yr}$ (model years 1979-99) of simulations of the climate of the twentieth century (20C3M) from 22 IPCC AR4 CGCMs. Table 1 lists the model names and acronyms, their horizontal and vertical resolutions, and brief descriptions of their deep convection schemes. Models with the same or similar deep convection schemes are listed together in Table 1 and in all the figures in this paper. For each model we use 20 yr of monthly mean surface precipitation. In addition, daily precipitation is available for 12 of the models, and we use 8 yr of daily data from each model to study the intraseasonal variability.
The model simulations are validated using the Global Precipitation Climatology Project (GPCP) version 2 precipitation data (Adler et al. 2003; Huffman et al. 2001). We use 21 yr (1979-99) of monthly data with a horizontal resolution of $2.5^{\circ}$ longitude by $2.5^{\circ}$ latitude, and 8 yr (1997-2004) of daily data with a horizontal resolution of $1^{\circ}$ longitude by $1^{\circ}$ latitude.

It is important to note that currently there are still large uncertainties associated with global precipitation analyses such as the GPCP dataset used in this study. The uncertainties come from many different sources, especially the lack of in situ measurement in certain geographical regions. Many efforts are being taken to reduce these uncertainties, especially with the aid of the extensive measurements from recent field experiments such as NAME and the East Pacific Investigation of Climate (EPIC).

\section{Method}

The MJO is defined as significant rainfall variability in eastward zonal wavenumbers 1-6 and in the period range of 24-70 days. It is isolated using the following procedure. (i) The 8 yr (2922 days) of daily precipitation data were averaged along the latitude belt between $5^{\circ}$ and $25^{\circ} \mathrm{N}$, where the eastward propagation of MJO mainly occurs during northern summer. We analyzed the intraseasonal variance of the entire latitude circle. All data were first linearly interpolated to a fine zonal resolution of $1^{\circ}$ longitude, and then averaged over each $10^{\circ}$ grid box. (ii) The space-time spectrum was calculated using a discrete Fourier transform for the whole 8 -yr time series. (iii) We then used an inverse spacetime Fourier transform to get the time series of the eastward component for wavenumbers 1-6, which includes all available frequencies. (iv) These time series were filtered using a 365-point 24-70-day Lanczos filter (Duchon 1979), whose response function was shown in Lin et al. (2006). Because the Lanczos filter is nonrecursive, 182 days of data were lost at each end of the original time series (days 1-182 and 2741-2922), so the length of the time series became 2558 days. (v) The resultant eastward wavenumber 1-6, 24-70-day anomaly during northern summer (May-October) is hereafter referred to as the MJO anomaly. (vi) Its variance was also compared with the variance of its westward counterpart (i.e., the westward wavenumber 1-6, 24-70-day anomaly), which was isolated using the same method as above.

The procedure for isolating the westward-propagating easterly waves is also same as above except for the westward wavenumber 6 and up, 3-6-day mode (Kila- 


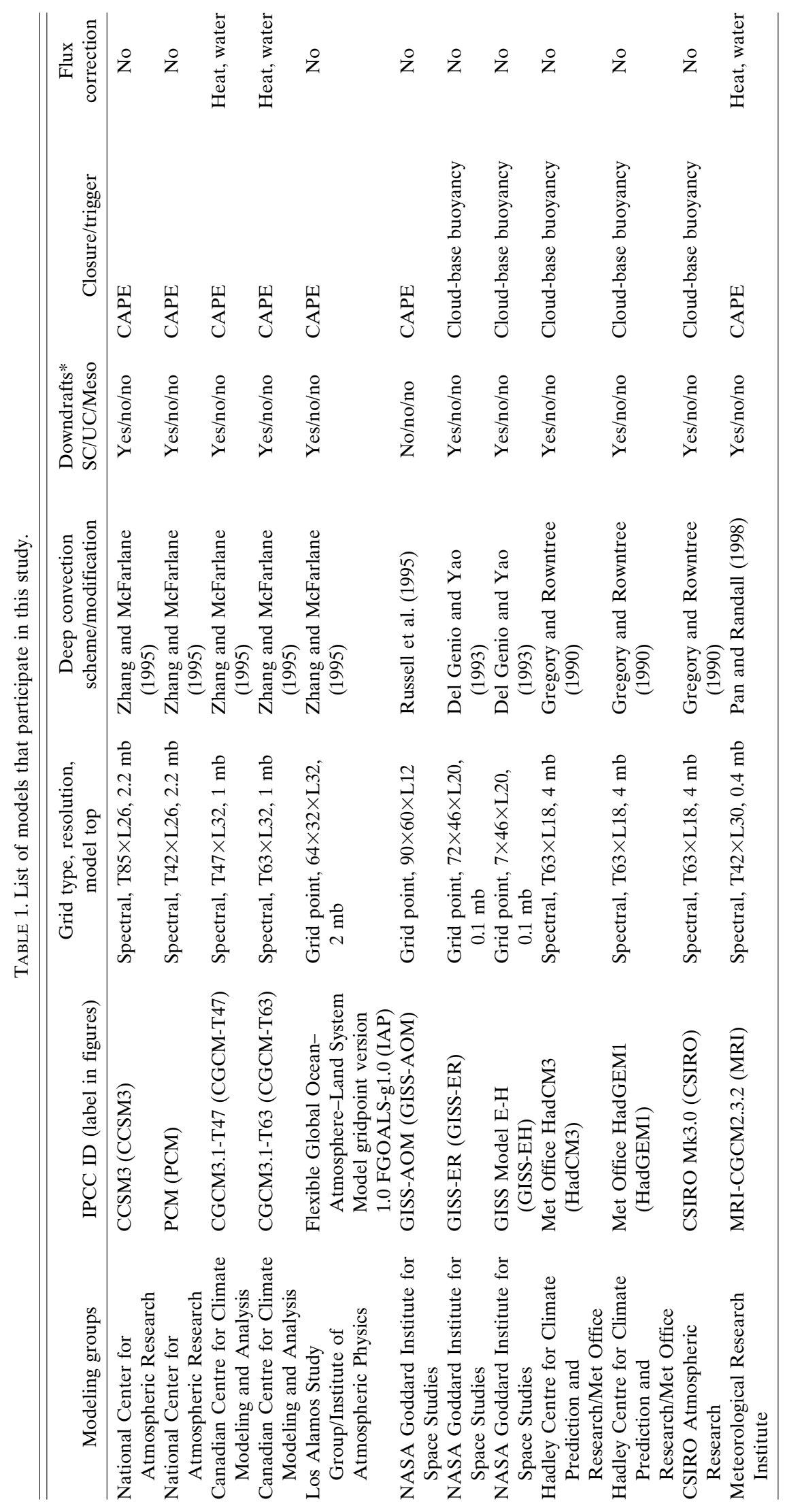




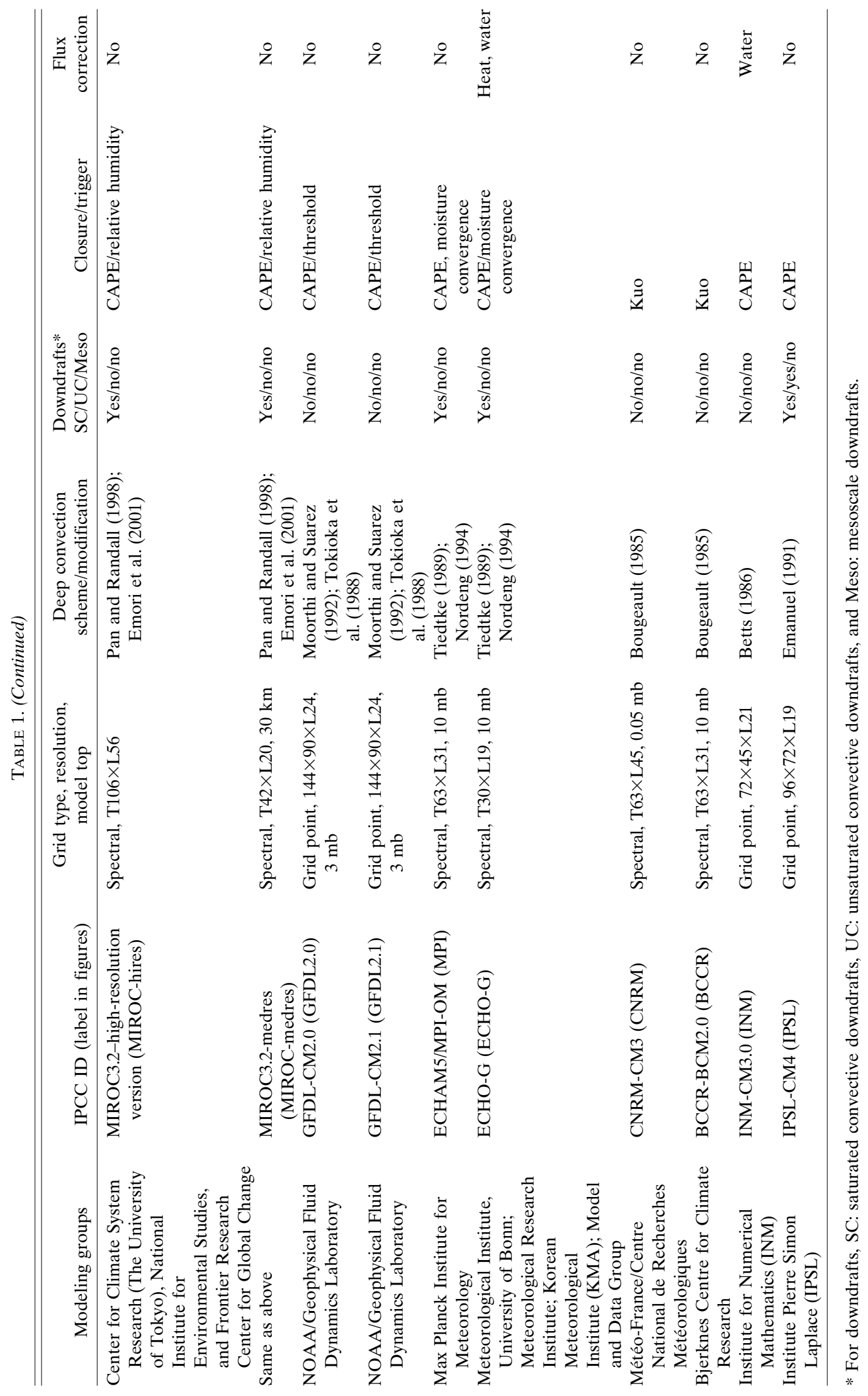


(a) Northern

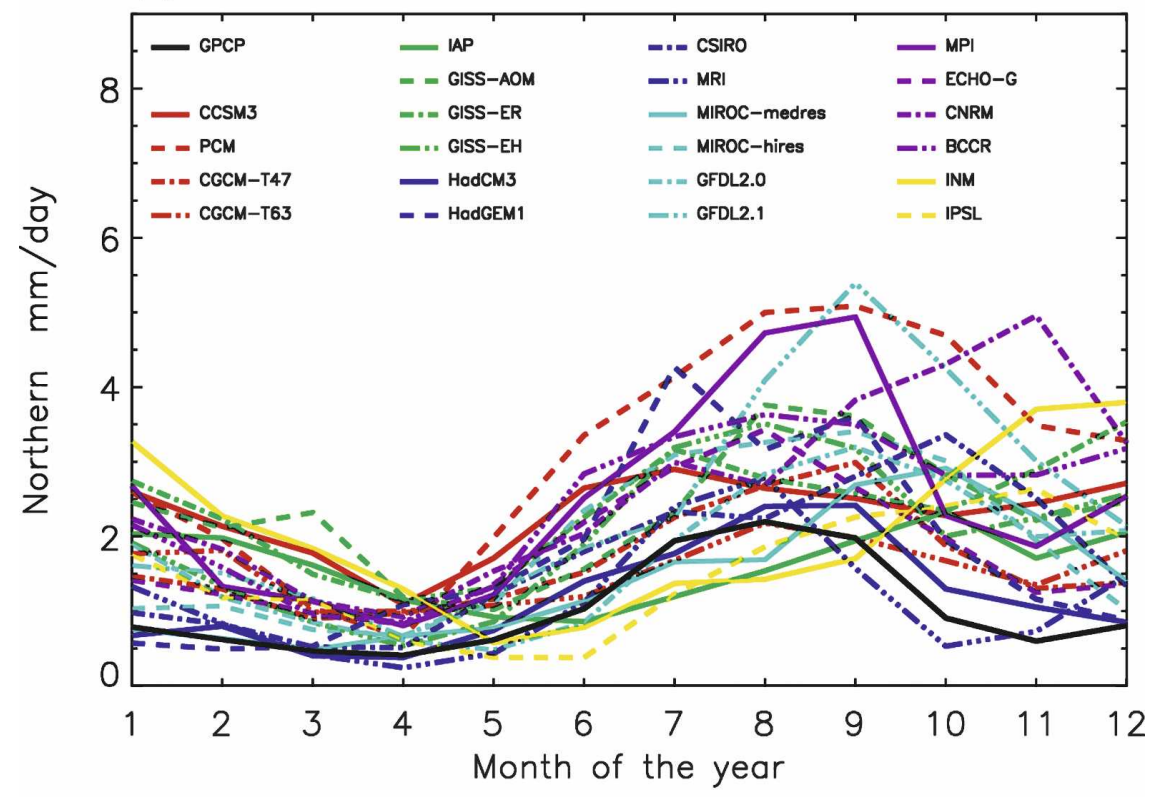

(b) Southern

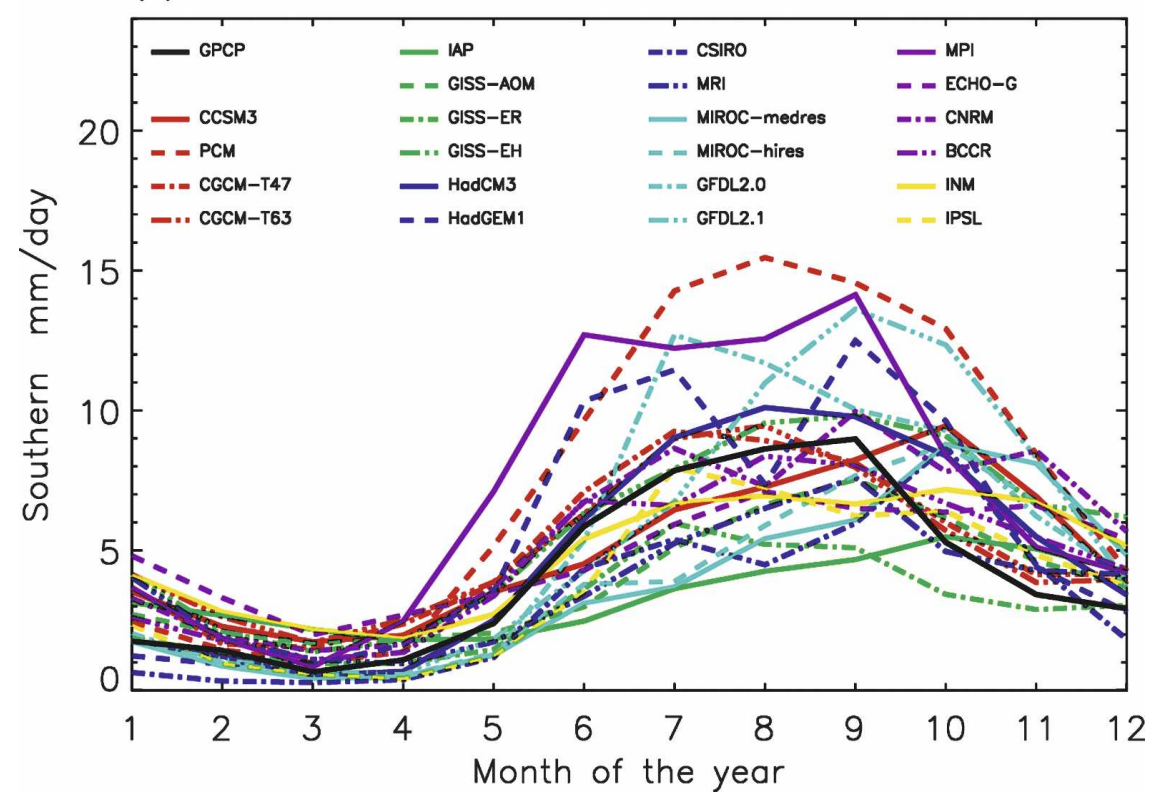

FIG. 2. Seasonal variation of precipitation averaged over (a) the core region of North American monsoon between $20^{\circ}-32.5^{\circ} \mathrm{N}$ and $100^{\circ}-115^{\circ} \mathrm{W}$, and (b) the eastern Pacific warm pool region between $10^{\circ}-20^{\circ} \mathrm{N}$ and $100^{\circ}-115^{\circ} \mathrm{W}$.

dis et al. 2006). This filter is close to the tropical depression (TD) band isolated in Wheeler and Kiladis (1999) and used in the Kiladis et al. (2006) study of African easterly waves. The methodology effectively excludes most variability associated with other westward waves, the 6-day cutoff eliminates equatorial Rossby waves, the 3-day cutoff eliminates westward in- ertio-gravity (WIG) waves, and the westward wavenumber 6 cutoff eliminates MRG waves. After the space-time filtering, the variance of the easterly waves was also compared with the variance of its eastwardpropagating counterpart (i.e., the eastward wavenumber 6 and up, 3-6-day anomaly), which was isolated using the same method as above. 


\section{Results}

\section{a. Seasonal variation of precipitation}

Figure 2a shows the seasonal cycle of precipitation averaged over the core region of the North American monsoon between $20^{\circ}-32.5^{\circ} \mathrm{N}$ and $100^{\circ}-115^{\circ} \mathrm{W}$ for observations and 22 IPCC AR4 CGCMs. Figure 2a demonstrates three points. First, the models display a large scatter in precipitation amplitude, with most of the models producing excessive precipitation throughout the entire seasonal cycle. Second, in observations the monsoon onset is in July, but the models display a wide range of onset time, with many models having a June onset [e.g., the Parallel Climate Model (PCM), the Bjerknes Centre for Climate Research model (BCCR), and the Community Climate System Model, version 3 (CCSM3)]. Third, in observations the monsoon ends in October, but many models keep the high monsoon precipitation until the end of the year [e.g., the Centre National de Recherches Météorologiques Coupled Global Climate Model, version 3 (CNRM-CM3), PCM, the Goddard Institute for Space Studies Model E-R (GISS-ER), BCCR, and CCSM3).]

Figure $2 b$ is the same as Fig. 2a but for the eastern Pacific warm pool region between $10^{\circ}-20^{\circ} \mathrm{N}$ and $100^{\circ}-115^{\circ} \mathrm{W}$. In contrast to the excessive precipitation over the core region of the North American monsoon, many models produce insufficient precipitation over the eastern $\mathrm{Pa}$ cific warm pool. The observed monsoon onset time is June in this region, which is reproduced by many models. However, the observed ending of the monsoon in October is not well reproduced by many models, which tend to keep high precipitation until the end of the year.

To examine the northward/southward shift of monsoon precipitation, Fig. 3 shows the seasonal cycle of precipitation along the longitude belt between $100^{\circ}$ and $115^{\circ} \mathrm{W}$. In observations (Fig. 3a, repeated in Fig. $3 \mathrm{~m}$ ), the precipitation displays a gradual northward shift from March to July and a gradual southward shift from August to November. The model simulations show two characteristics. First, although many models can reproduce the gradual northward shift [e.g., CGCM-T47, the Institute of Atmospheric Physics (IAP) model, the Goddard Institute for Space Studies AtmosphereOcean Model (GISS-AOM), the Third Hadley Centre Coupled Ocean-Atmosphere GCM (HadCM3), the Geophysical Fluid Dynamics Laboratory Climate Model, version 2.0 (GFDL CM2.0), and the Max Planck Institute Ocean Model (MPI-OM)], there are quite a few models which produce a (nearly) simultaneous increase of precipitation in northern and southern latitudes in early summer (e.g., PCM, GISS-ER,
GFDL CM2.1, CNRM-CM3, and BCCR), corresponding to the too-early monsoon onset in those models over the core region of the North American monsoon (Fig. 2a). Second, most of the models fail to reproduce the gradual southward shift of precipitation from $\mathrm{Au}-$ gust to November and keep high precipitation in the northern latitudes until the end of the year. There is no obvious correspondence between models that fail to reproduce the monsoon retreat and those simulating a too-early monsoon onset.

Next we look at the horizontal pattern of precipitation in July when the monsoon is at its peak (Fig. 4). The observed precipitation (Fig. 4a, repeated in Fig. $4 \mathrm{~m})$ displays a rainbelt extending from southeast to northwest. Most of the models produce the rainbelt, suggesting that the models can capture the basic mechanism for the formation of the North American monsoon, although the magnitude is often too large. In addition, in several models the simulated rainbelt is isolated from the precipitation over the eastern Pacific warm pool, which is different from observations [e.g., the Commonwealth Scientific and Industrial Research Organisation (CSIRO) Mark, version 3.0 (Mk3.0), and the Model for Interdisciplinary Research on Climate, medium-resolution version (MIROC-medres)].

\section{b. The MJO}

Now we focus on the variance of the MJO, that is, the daily variance of the eastward wavenumber 1-6, 24-70day mode. Figure 5 shows that the MJO variance along the equator averaged between $5^{\circ}$ and $25^{\circ} \mathrm{N}$. In observations, MJO variance has its maximum over the eastern Pacific warm pool. The model variance approaches the observed value in only one model (ECHAM5/MPI$\mathrm{OM})$, but is less than half of the observed value in all other 11 models. This is similar to the performance of these models in simulating the all-season MJO over the Indian Ocean and western Pacific, for which the simulated variance is less than half of the observed value in 10 of the 12 models (Lin et al. 2006).

In addition to the variance, another important index for evaluating the MJO simulation is the ratio between the variance of the eastward MJO and that of its westward counterpart (i.e., the westward wavenumber $1-6$, 24-70-day mode), which is important for the zonal propagation of tropical intraseasonal oscillation. Figure 6 shows the ratio between the eastward variance and the westward variance averaged over an eastern Pacific box between $5^{\circ}-25^{\circ} \mathrm{N}$ and $100^{\circ}-140^{\circ} \mathrm{W}$. In the observation, the eastward MJO variance is double that of the westward variance. The 12 models may be divided into two groups. Seven models simulate a ratio larger than or close to one [CSIRO Mk3.0, the Meteo- 

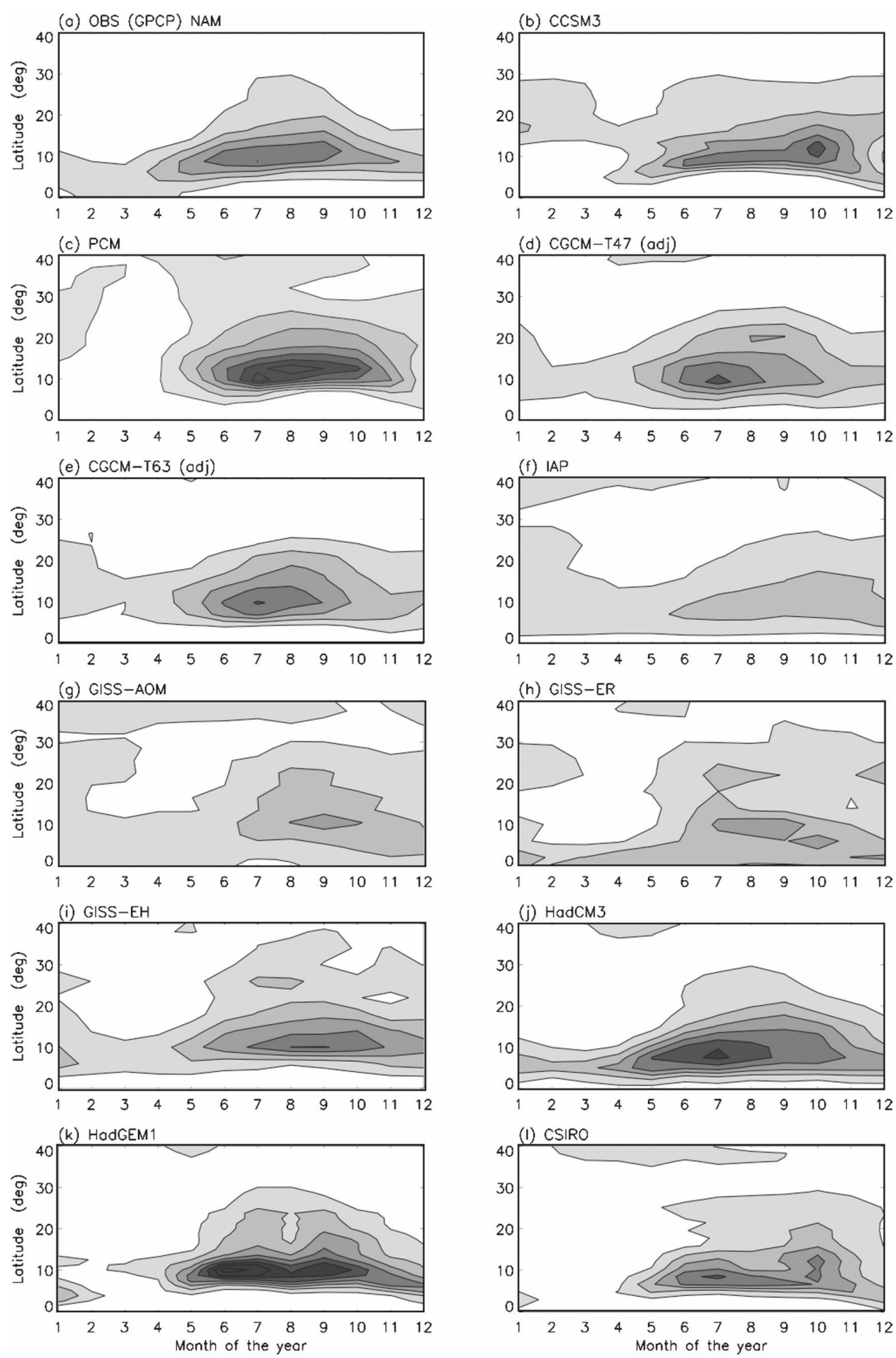

FIG. 3. Seasonal variation of precipitation averaged between $100^{\circ}$ and $115^{\circ} \mathrm{W}$ for the observations and 22 models.

rological Research Institute (MRI) CGCM, MIROCmedres, GFDL CM2.0 and GFDL CM2.1, MPI-OM, and CNRM-CM3], and the others simulate a ratio much less than one (i.e., westward variance dominates over eastward variance). Interestingly, the models in the second group all have undiluted updrafts in their deep convection scheme, while none of those in the first group have undiluted updrafts. This suggests that re- 

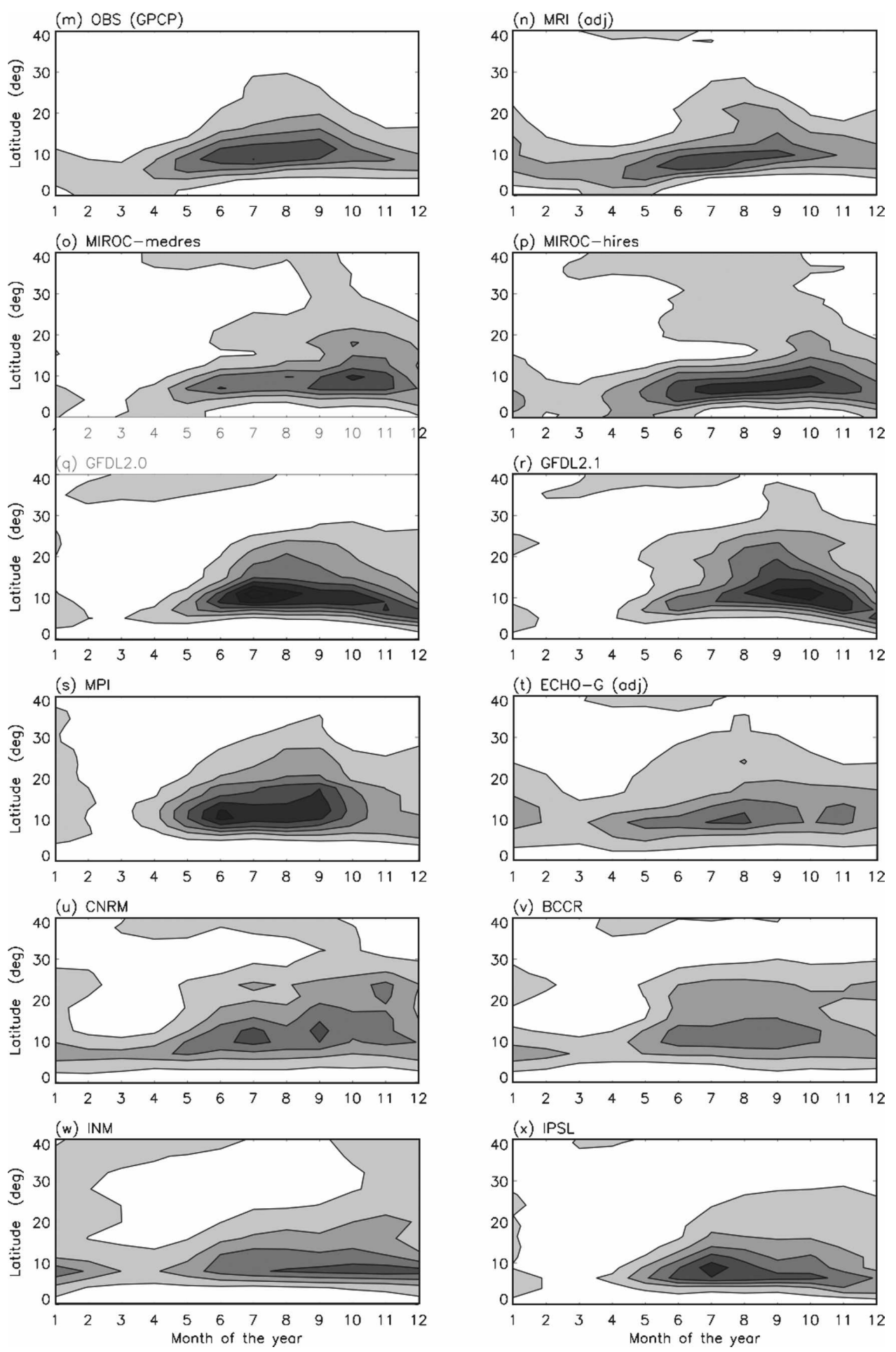

FIG. 3. (Continued)

moving undiluted updrafts may help improve the propagation of the MJO in GCMs.

The competition between the eastward MJO variance and its westward counterpart largely determines the zonal propagation characteristics of the tropical in- traseasonal oscillation. When the ratio is much more (less) than one, most of the tropical intraseasonal oscillation events will propagate eastward (westward). A useful method for evaluating the MJO simulation is to look at the propagation of the 24-70-day filtered 

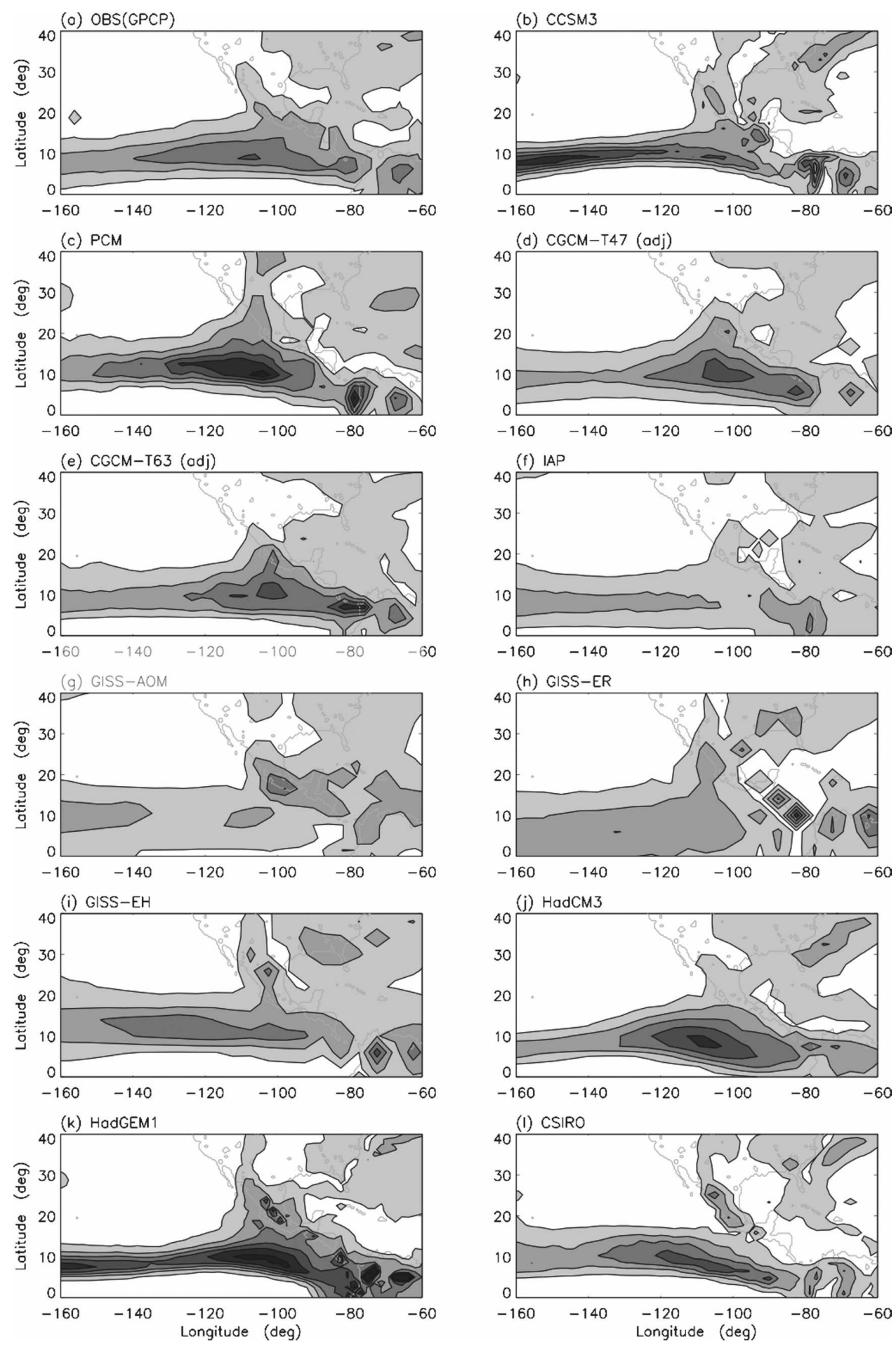

FIG. 4. July mean precipitation for the observations (GPCP) and 22 models.

anomaly of the raw precipitation data, which includes all wavenumbers, to see if the MJO mode (the eastward wavenumber 1-6 mode) dominates over the other modes, as is the case in the observations. Because the tropical intraseasonal oscillation is dominated by zon- ally asymmetric, planetary-scale phenomena, the competition is mainly between the MJO and its westward counterpart-the westward wavenumber 1-6 component. Figure 7 shows the lag correlation of the 24-70day precipitation anomaly averaged between $5^{\circ}$ and 

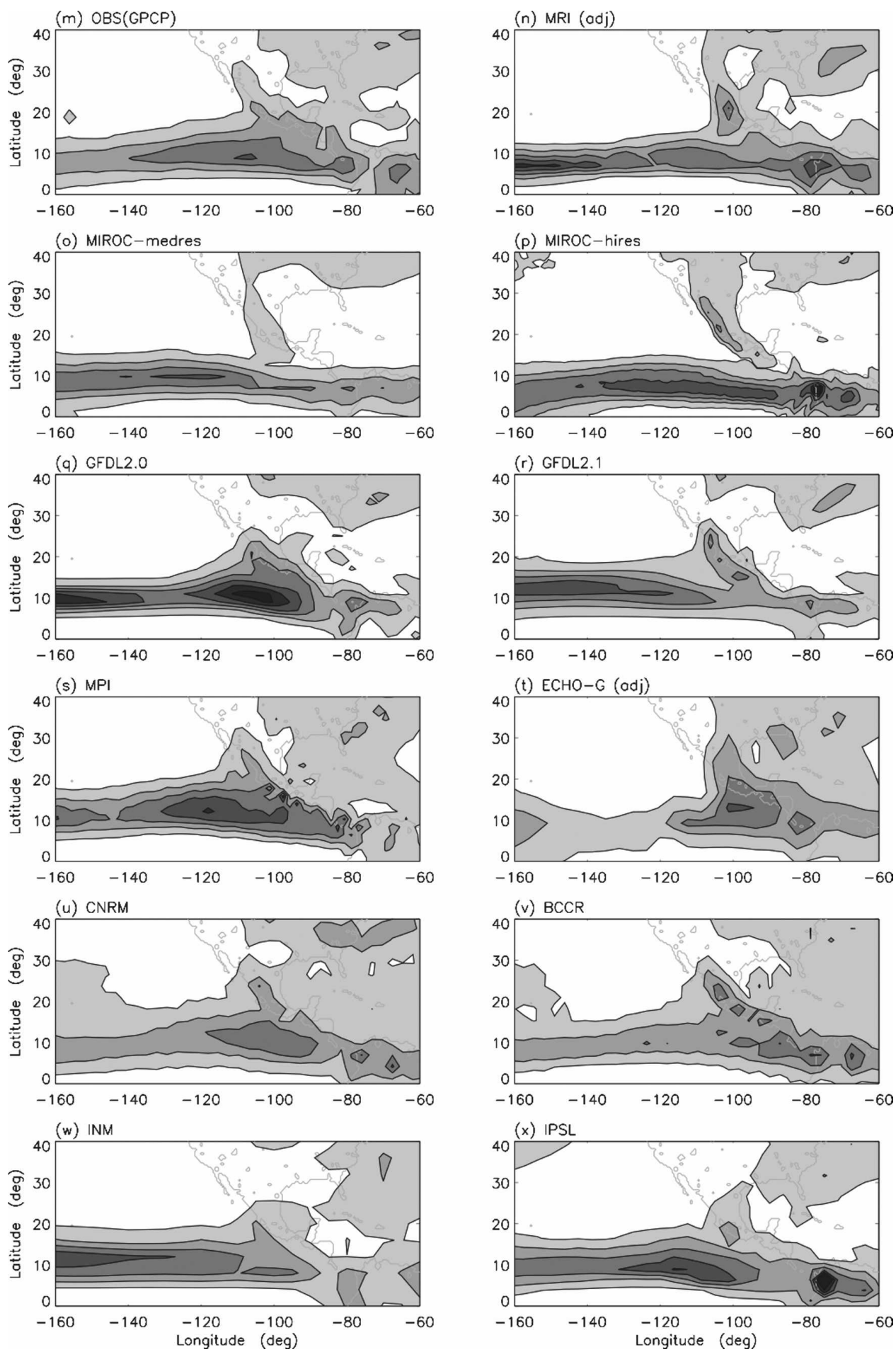

FIG. 4. (Continued)

$25^{\circ} \mathrm{N}$ with respect to itself at $10^{\circ} \mathrm{N}, 255^{\circ} \mathrm{E}$. The observational data show prominent eastward-propagating signals of the MJO, with a phase speed of about 5 $\mathrm{m} \mathrm{s}^{-1}$. The models display a wide range of propagation characteristics that are consistent with the ratio be- tween the eastward MJO variance and its westward counterpart shown in Fig. 6. The three models with a ratio larger than 1.5 (CSIRO Mk3.0, GFDL2.0, and GFDL2.1) show a discernable eastward-propagating signal, but other models with the eastward/ 


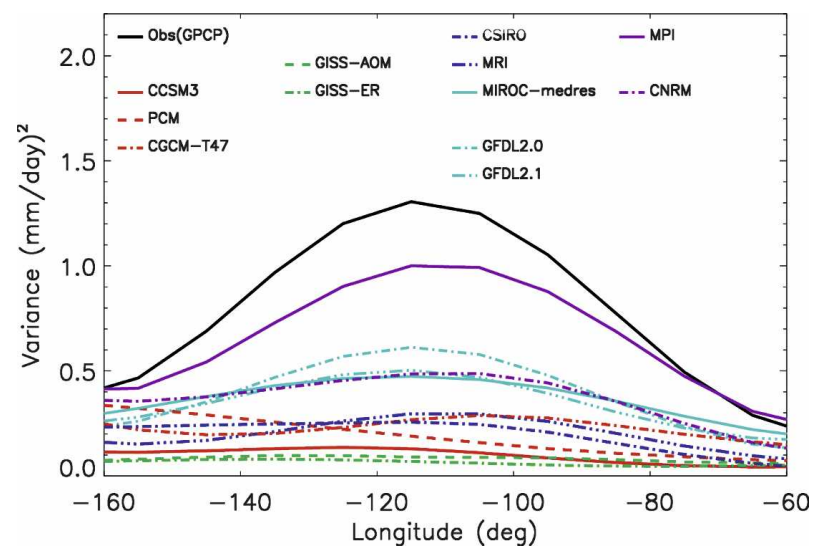

FIG. 5. Variance of the $\mathrm{MJO}$ averaged between $5^{\circ}$ and $25^{\circ} \mathrm{N}$ for May-October.

westward ratio nearly equal to one or less than one show a standing oscillation (e.g., PCM and MRI CGCM) or westward propagation (e.g., GISS-AOM and GISS-ER).

In addition to the eastward-propagating component, the MJO also has a slow northward-propagating component, which takes the MJO signals from near the equator to the core North American monsoon region. Figure 8 shows the lag correlation of the 24-70-day precipitation anomaly along the latitude belt averaged between $100^{\circ}$ and $115^{\circ} \mathrm{W}$ with respect to itself at $12^{\circ} \mathrm{N}$, $107^{\circ} \mathrm{W}$. The observational data show highly coherent northward-propagating signals of the MJO, with a phase speed of about $2.5 \mathrm{~m} \mathrm{~s}^{-1}$. Eight of the 12 models simulate coherent northward propagation (PCM, CGCM, CSIRO Mk3.0, MRI CGCM, MIROC-medres, GFDL2.0, GFDL2.1 and MPI-OM) but sometimes with a too-fast phase speed. The other four models show a standing oscillation (CCSM3, CNRM-CM3) or even southward propagation (GISS-AOM, GISS-ER). There is no one-to-one correspondence between models with good northward propagation and those with good eastward propagation.

\section{c. Easterly waves}

Figure 9 shows the variance of easterly waves averaged between $10^{\circ}$ and $20^{\circ} \mathrm{N}$. Two of the 12 models (MPI-OM and CNRM-CM3) simulate nearly realistic variance of easterly waves, although the maximum is shifted slightly to the west for the MPI-OM. However, all other 10 models produce variance that is less than half of the observed value.

Figure 10 shows the ratio between the variance of the westward-propagating easterly waves and that of its eastward-propagating counterpart averaged over an

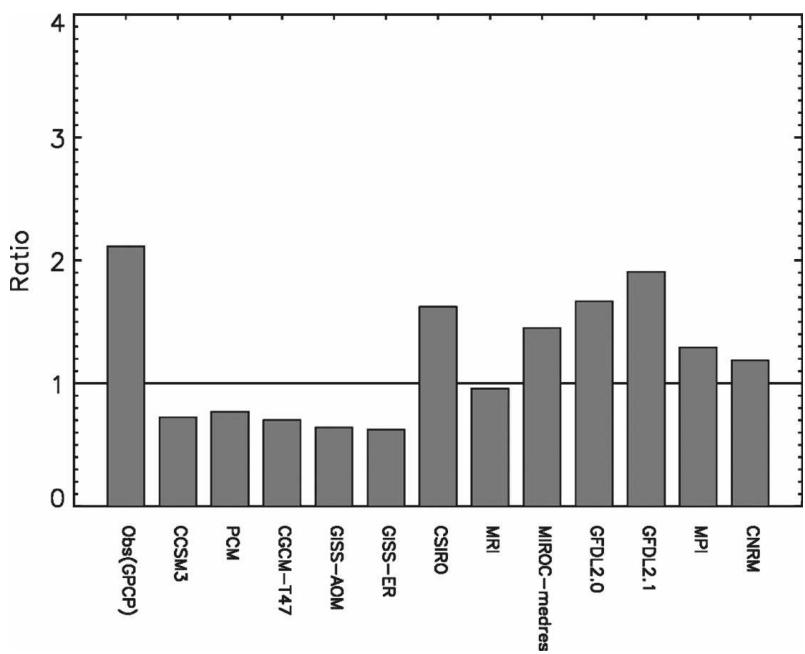

FIG. 6. Ratio between the variance of the MJO and the variance of its westward counterpart (westward wavenumber 1-6, 24-70day mode). The variances are averaged over an eastern Pacific box between $5^{\circ}-25^{\circ} \mathrm{N}$ and $100^{\circ}-140^{\circ} \mathrm{W}$ for May-October.

eastern Pacific box between $10^{\circ}-20^{\circ} \mathrm{N}$ and $70^{\circ}-120^{\circ} \mathrm{W}$. In the observation, the westward variance roughly doubles the eastward variance. All models simulate a ratio larger than one (i.e., westward variance dominates over eastward variance), and three of the models simulate an overly large ratio (MRI CGCM, MPI-OM, and CNRM-CM3). Consistently, most of the models display a highly coherent westward propagation of easterly waves (not shown).

\section{Summary and discussion}

This study evaluates the fidelity of North American monsoon and associated intraseasonal variability in IPCC AR4 CGCMs. Twenty years of monthly precipitation data from each of the 22 models' twentiethcentury climate simulation, together with the available daily precipitation data from 12 of them, are analyzed and compared with GPCP monthly and daily precipitation data. We focus on the seasonal cycle and horizontal pattern of monsoon precipitation, together with the two dominant intraseasonal modes: the eastwardpropagating $\mathrm{MJO}$ and the westward-propagating easterly waves.

The results show that the IPCC AR4 CGCMs have significant problems and display a wide range of skill in simulating the North American monsoon and associated intraseasonal variability. Most of the models reproduce the monsoon rainbelt extending from southeast to northwest and its gradual northward shift in early summer but overestimate the precipitation over the core monsoon region throughout the seasonal cycle 

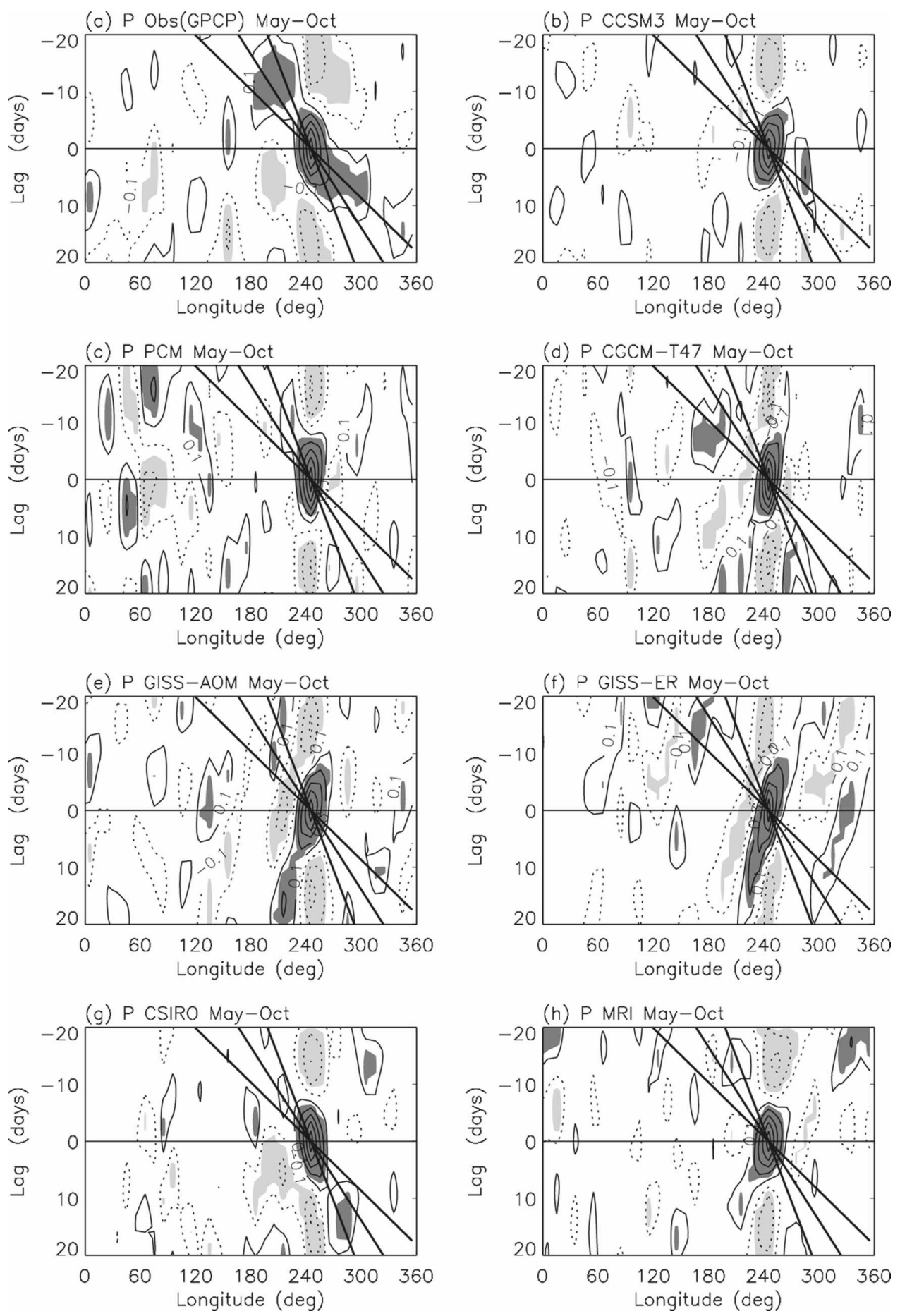

FIG. 7. Lag correlation of the 24-70-day precipitation anomaly averaged between $5^{\circ}$ and $25^{\circ} \mathrm{N}$ with respect to itself at $15^{\circ} \mathrm{N}, 245^{\circ} \mathrm{E}$. Shading denotes the regions where lag correlation is above the $95 \%$ confidence level. The three thick lines correspond to phase speeds of 3,5 , and $8 \mathrm{~m} \mathrm{~s}^{-1}$, respectively.

and fail to reproduce the monsoon retreat in the fall. Most models simulate good westward propagation of the easterly waves but relatively poor eastward propagation of the MJO and overly weak variances for both the easterly waves and the MJO. There is a tendency for models without undiluted updrafts in their deep convection scheme to produce better MJO propagation. 

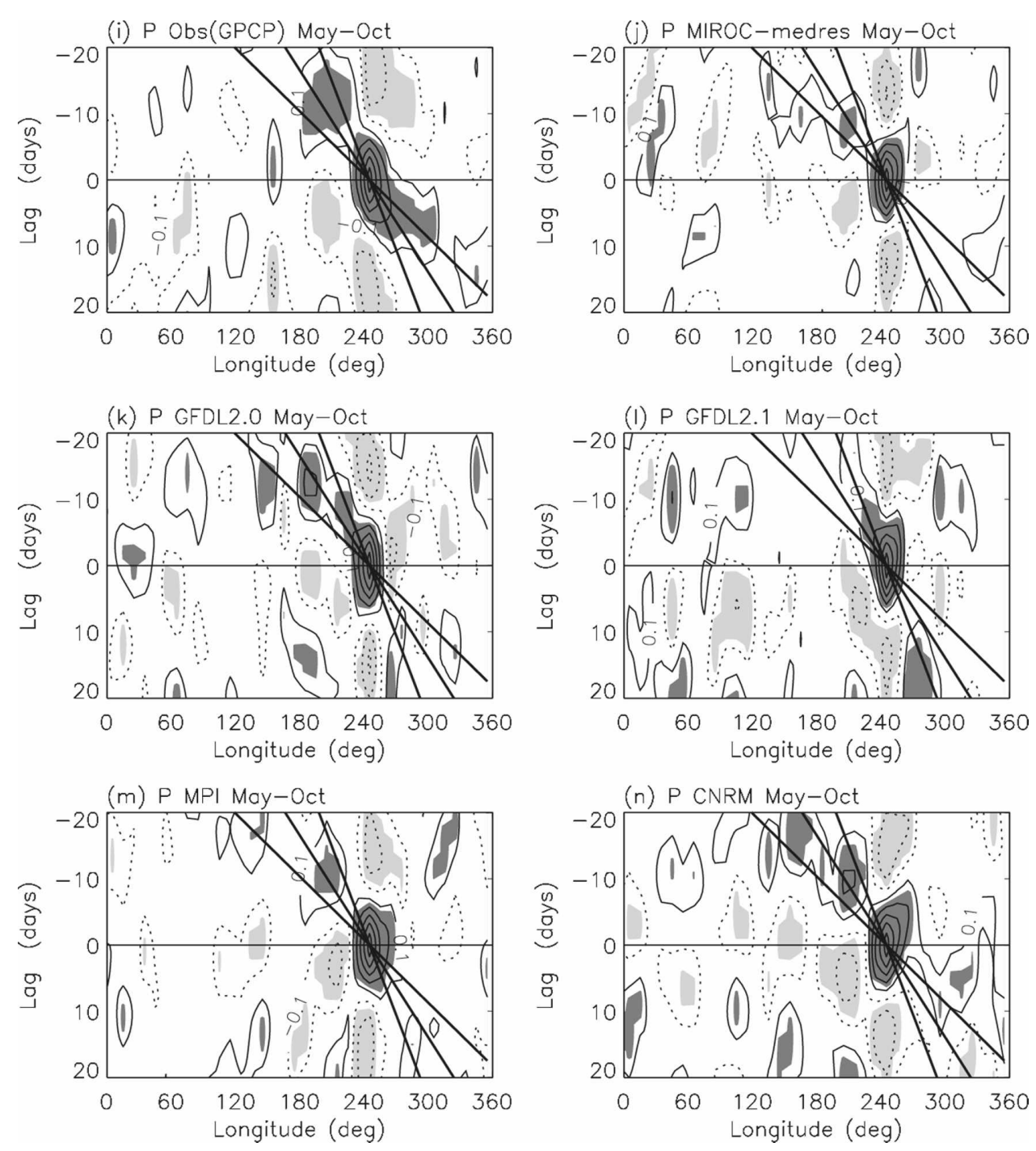

FIG. 7. (Continued)

The 22 models provide a large variety of model physics, such as all the major deep convection schemes with different types of convective closures, convective triggers, and cloud models (Table 1). Recall that models with the same or similar deep convection schemes are listed together in Table 1 and in all the figures in this paper. For the seasonal cycle and horizontal pattern of the North American monsoon, we do not find any systematic dependence of model simulations on the type of closure assumptions or cloud models. For the intraseasonal variability, however, the two models with the largest variances of easterly waves (MPI-OM and CNRM-CM3; Fig. 9) are the only models with their convective closure/trigger linked in some way to moisture convergence. The MPI-OM also produces the largest northern summer MJO variance in the North
American monsoon region (Fig. 5); additionally, these two models simulate the largest all-season MJO variances over the Indian Ocean and western Pacific (Lin et al. 2006). Therefore, the moisture convergence closure/ trigger seems to be helpful for enhancing the variances of the MJO and easterly waves in GCMs. This is inconsistent with the results of Slingo et al. (1996), who found that for the Atmospheric Model Intercomparison Project (AMIP) models, deep convection schemes with CAPE-type closure tend to produce larger MJO signals than schemes with moisture convergence-type closure.

Another interesting finding of this study is that convection schemes without undiluted updrafts tend to produce better eastward propagation of the MJO. Removing undiluted updrafts may help to better represent the shallow convective clouds and associated premoist- 

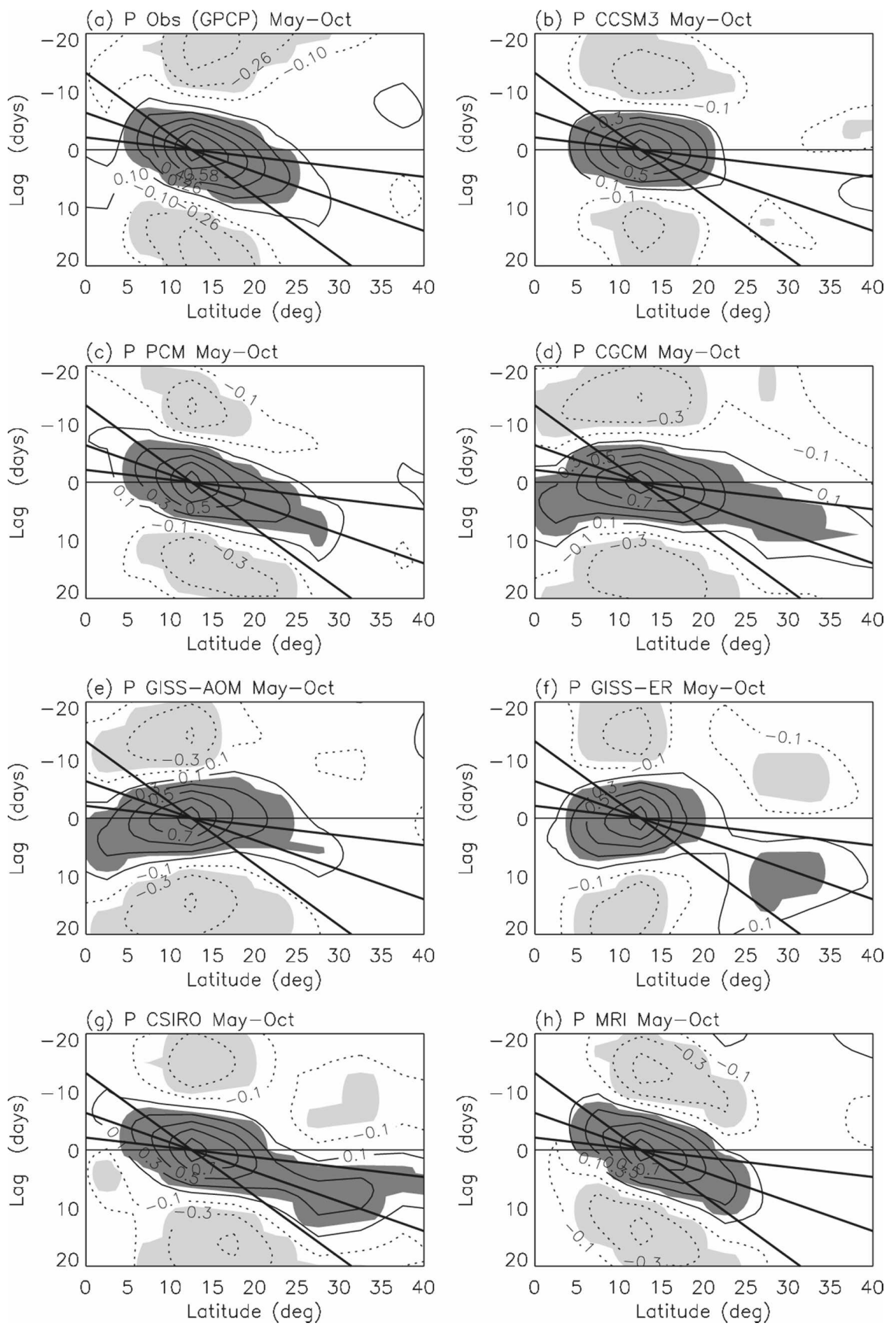

FIG. 8. Lag correlation of the 24-70-day precipitation anomaly averaged between $100^{\circ}$ and $115^{\circ} \mathrm{W}$ with respect to itself at $12^{\circ} \mathrm{N}, 107^{\circ} \mathrm{E}$. Shading denotes the regions where lag correlation is above the $95 \%$ confidence level. The three thick lines correspond to phase speeds of $1.2,2.5$, and $7.5 \mathrm{~m} \mathrm{~s}^{-1}$, respectively. 

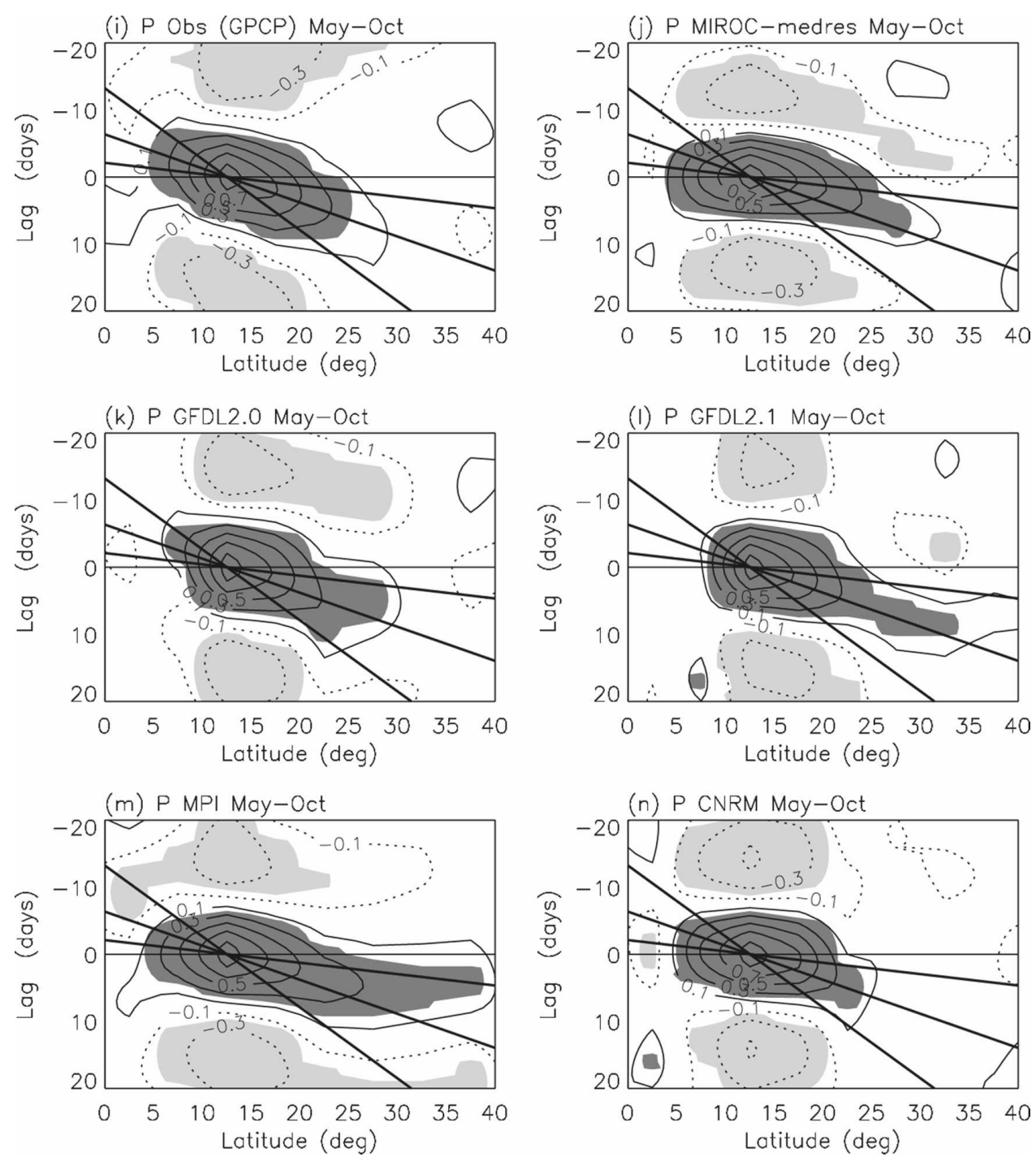

FIG. 8. (Continued)

ening in the early stage of the MJO (e.g., Johnson et al. 1999; Lin et al. 2004), which have been shown by theoretical models to be important for the MJO propagation (e.g., Mapes et al. 2006; Khouider and Majda 2006a,b, 2007).

The ocean model also plays some role in simulating the North American monsoon. Evidence comes from comparisons between GISS-ER and GISS-EH, which have the same atmospheric model but different ocean models. GISS-EH arguably produces a better seasonal cycle (Figs. 3i,j) and horizontal pattern (Figs. 4i,j). The effects of the ocean model are very complicated. Possible effects include costal upwelling, horizontal advection, mixing processes, and ocean-atmosphere feedbacks, which are beyond the scope of the present study.

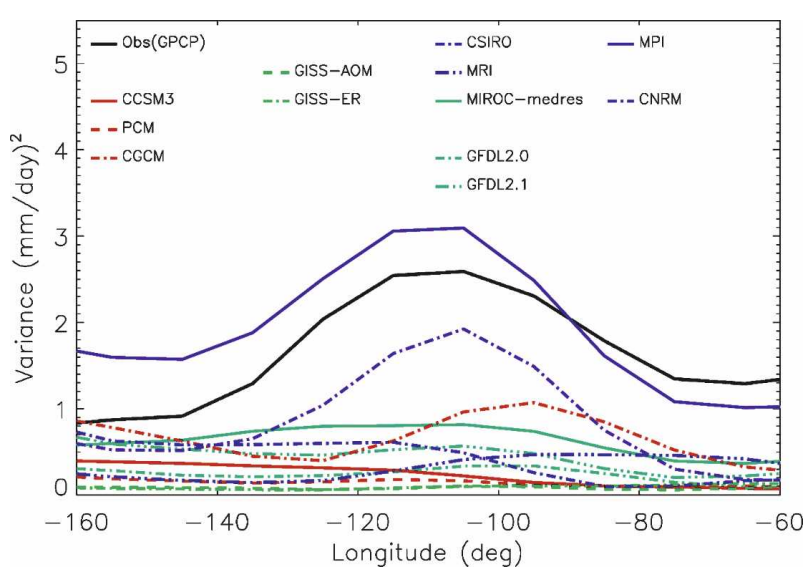

FIG. 9. Variance of easterly waves averaged between $10^{\circ}$ and $20^{\circ} \mathrm{N}$ for May-October. 


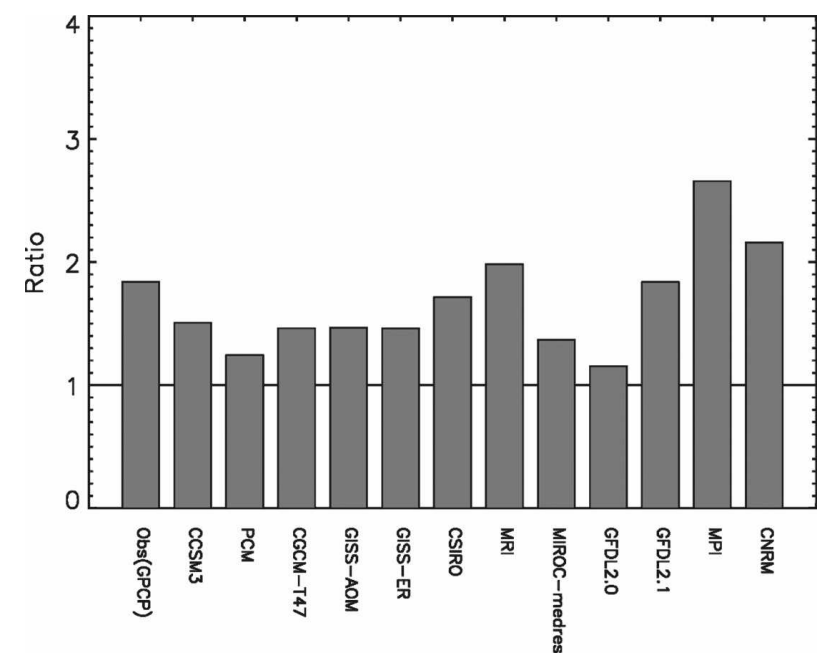

FIG. 10. Ratio between the variance of the westwardpropagating easterly waves and the variance of its eastwardpropagating counterpart (eastward 3-6-day mode). The variances are averaged over $10^{\circ}-20^{\circ} \mathrm{N}$ and $70^{\circ}-120^{\circ} \mathrm{W}$ for May-October.

Many previous studies have shown that time mean precipitation is important for intraseasonal variability in GCMs (e.g., Inness and Slingo 2003; Sperber 2004). It is interesting, therefore, to compare the simulation of seasonal variation of precipitation and the simulation of subseasonal convectively coupled equatorial waves in the IPCC models. We want to address two questions. First, does larger seasonal mean precipitation in the models correspond to stronger intraseasonal variability? Our results give a negative answer. Although the MPI-OM does show both a large seasonal mean and strong intraseasonal variability, the PCM shows a large seasonal mean but a very weak intraseasonal variability (Figs. 2 and 5). Second, does good northward propagation of the MJO lead to better simulation of the seasonal northward shift of the rainbelt and monsoon onset in the core monsoon region? We did not find such a relationship in our results. The eight models simulating coherent northward MJO propagation (Fig. 8; PCM, CGCM, CSIRO Mk3.0, MRI CGCM, MIROC-medres, GFDL2.0, GFDL2.1, and MPI-OM) display different characteristics of the seasonally northward shift of the rainbelt (Fig. 3) from gradual propagation (e.g., CGCM-T47) to a sudden jump (e.g., PCM). Therefore, the simulation of seasonal variation and the simulation of intraseasonal variability seem to be different questions, which are possibly related to different model characteristics.

Moreover, the North American monsoon system is an open system and is strongly affected by the whole tropical mean climate. Previous studies have shown that significant biases in tropical mean climate, espe- cially the well-known double-ITCZ problem, exist in the IPCC AR4 models (Lin 2007). Therefore, improving the simulation of the entire tropical mean climate may help to improve the simulation of the North American monsoon system.

Acknowledgments. Gary Russell kindly provided a detailed description of the GISS-AOM model. We acknowledge the international modeling groups for providing their data for analysis, the Program for Climate Model Diagnosis and Intercomparison (PCMDI) for collecting and archiving the model data, the JSC/ CLIVAR Working Group on Coupled Modeling (WGCM) and their Coupled Model Intercomparison Project (CMIP) and Climate Simulation Panel for organizing the model data analysis activity, and the IPCC WG1 TSU for technical support. The IPCC Data Archive at Lawrence Livermore National Laboratory is supported by the Office of Science, U.S. Department of Energy. J. L. Lin was supported by the U.S. CLIVAR CMEP, NOAA CPO/CVP Program, NOAA CPO/ CDEP Program, and NASA MAP Program. B. E. Mapes was supported by the NOAA CPO/CVP program and by CPO/CPPA Grant GC05-039. G. N. Kiladis was supported by NOAA CPO under Grant GC05-156.

\section{REFERENCES}

AchutaRao, K., and K. R. Sperber, 2006: ENSO simulation in coupled ocean-atmosphere models: Are the current models better? Climate Dyn., 27, 1-15, doi:10.1007/s00382-0060119-7.

Adams, D. K., and A. C. Comrie, 1997: The North American monsoon. Bull. Amer. Meteor. Soc., 78, 2197-2213.

Adams, J. L., and D. J. Stensrud, 2007: Impact of tropical easterly waves on the North American monsoon. J. Climate, 20, 12191238.

Adler, R. F., and Coauthors, 2003: The version-2 Global Precipitation Climatology Project (GPCP) monthly precipitation analysis (1979-present). J. Hydrometeor., 4, 1147-1167.

Anderson, B. T., J. O. Roads, and S.-C. Chen, 2000: Large-scale forcing of summertime monsoon surges over the Gulf of California and southwestern United States. J. Geophys. Res., 105 (D19), 24 455-24 467.

Arritt, R. W., D. C. Goering, and C. J. Anderson, 2000: The North American monsoon system in the Hadley Centre coupled ocean-atmosphere GCM. Geophys. Res. Lett., 27, 565-568.

Avila, L. A., 1991: Eastern North Pacific hurricane season of 1990. Mon. Wea. Rev., 119, 2034-2046.

—_, and R. J. Pasch, 1992: Atlantic tropical systems of 1991. Mon. Wea. Rev., 120, 2688-2696.

Barlow, M., S. Nigam, and E. H. Berbery, 1998: Evolution of the North American monsoon system. J. Climate, 11, 2238-2257.

Berbery, E. H., and M. S. Fox-Rabinovitz, 2003: Multiscale diagnosis of the North American monsoon system using a variable-resolution GCM. J. Climate, 16, 1929-1947.

Betts, A. K., 1986: A new convective adjustment scheme. Part I: 
Observational and theoretical basis. Quart. J. Roy. Meteor. Soc., 112, 677-691.

Bougeault, P., 1985: A simple parameterization of the large-scale effects of cumulus convection. Mon. Wea. Rev., 113, 21082121.

Capotondi, A., A. Wittenberg, and S. Masina, 2006: Spatial and temporal structure of tropical Pacific interannual variability in 20th century coupled simulations. Ocean Modell., 15, 274 298.

Collier, J. C., and G. J. Zhang, 2006: Simulation of the North American monsoon by the NCAR CCM3 and its sensitivity to convection parameterization. J. Climate, 19, 2851-2866.

Del Genio, A. D., and M.-S. Yao, 1993: Efficient cumulus parameterization for long-term climate studies: The GISS scheme. The Representation of Cumulus Convection in Numerical Models, Meteor. Monogr., No. 46, Amer. Meteor. Soc., 181184.

Douglas, M. W., R. A. Maddox, K. Howard, and S. Reyes, 1993: The Mexican monsoon. J. Climate, 6, 1665-1677.

Duchon, C. E., 1979: Lanczos filtering in one and two dimensions. J. Appl. Meteor., 18, 1016-1022.

Dunn, L. B., and J. D. Horel, 1994: Prediction of central Arizona convection. Part I: Evaluation of the NGM and Eta model precipitation forecasts. Wea. Forecasting, 9, 495-507.

Emanuel, K. A., 1991: A scheme for representing cumulus convection in large-scale models. J. Atmos. Sci., 48, 2313-2329.

Emori, S., T. Nozawa, A. Numaguti, and I. Uno, 2001: Importance of cumulus parameterization for precipitation simulation over East Asia in June. J. Meteor. Soc. Japan, 79, 939-947.

Farrara, J. D., and J. Yu, 2003: Interannual variations in the southwest U.S. monsoon and sea surface temperature anomalies: A general circulation model study. J. Climate, 16, 1703-1720.

Fuller, R. D., and D. J. Stensrud, 2000: The relationship between tropical easterly waves and surges over the Gulf of California during the North American monsoon. Mon. Wea. Rev., 128, 2983-2989.

Giorgi, F., 1991: Sensitivity of simulated summertime precipitation over the western United States to different physics parameterizations. Mon. Wea. Rev., 119, 2870-2888.

Gochis, D. J., W. J. Shuttleworth, and Z.-L. Yang, 2002: Sensitivity of the modeled North American monsoon regional climate to convective parameterization. Mon. Wea. Rev., 130, 1282-1298.

Gregory, D., and P. R. Rowntree, 1990: A mass flux convection scheme with representation of cloud ensemble characteristics and stability-dependent closure. Mon. Wea. Rev., 118, 14831506.

Gutzler, D. S., and Coauthors, 2005: The North American Monsoon Model Assessment Project: Integrating numerical modeling into a field-based process study. Bull. Amer. Meteor. Soc., 86, 1423-1429.

Higgins, R. W., and W. Shi, 2001: Intercomparison of the principal modes of interannual and intraseasonal variability of the North American monsoon system. J. Climate, 14, 403-417.

- , and NAME Science Working Group, 2003: The North American Monsoon Experiment (NAME): Science and implementation plan. NAME Project Science team, 91 pp. [Available from Climate Prediction Center, 5200 Auth Road, Camp Springs, MD 20746.]

_ , Y. Yao, and X. Wang, 1997: Influence of the North American monsoon system on the U.S. summer precipitation regime. J. Climate, 10, 2600-2622.
- , and Coauthors, 2006: The NAME 2004 field campaign and modeling strategy. Bull. Amer. Meteor. Soc., 87, 79-94.

Huffman, G. J., R. F. Adler, M. M. Morrissey, D. T. Bolvin, S. Curtis, R. Joyce, B. McGavock, and J. Susskind, 2001: Global precipitation at one-degree daily resolution from multisatellite observations. J. Hydrometeor., 2, 36-50.

Inness, P. M., and J. M. Slingo, 2003: Simulation of the MaddenJulian Oscillation in a coupled general circulation model. Part I: Comparison with observations and an atmosphereonly GCM. J. Climate, 16, 345-364.

Johnson, R. H., T. M. Rickenbach, S. A. Rutledge, P. E. Ciesielski, and W. H. Schubert, 1999: Trimodal characteristics of tropical convection. J. Climate, 12, 2397-2418.

Joseph, R., and S. Nigam, 2006: ENSO evolution and teleconnections in IPCC's twentieth-century climate simulations: Realistic representation? J. Climate, 19, 4360-4377.

Khouider, B., and A. J. Majda, 2006a: A simple multicloud parameterization for convectively coupled tropical waves. Part I: Linear analysis. J. Atmos. Sci., 63, 1308-1323.

$\longrightarrow$, and — 2006b: Model multicloud parametrizations for convectively coupled waves: Detailed nonlinear wave evolution. Dyn. Atmos. Oceans, 42, 59-80.

$\longrightarrow$, and — 2007: A simple multicloud parametrization for convectively coupled tropical waves. Part II: Nonlinear simulations. J. Atmos. Sci., 64, 381-400.

Kiladis, G. N., C. D. Thorncroft, and N. M. J. Hall, 2006: Threedimensional structure and dynamics of African easterly waves. Part I: Observations. J. Atmos. Sci., 63, 2212-2230.

Krishnamurti, T. N., D. Bachiochi, T. LaRow, B. Jha, M. Tewari, D. R. Chakraborty, R. Correa-Torres, and D. Oosterhof, 2000: Coupled atmosphere-ocean modeling of the El Niño of 1997-98. J. Climate, 13, 2428-2459.

Kunkel, K. E., 2003: Sea surface temperature forcing of the upward trend in U.S. extreme precipitation. J. Geophys. Res., 108, 4020, doi:10.10292002/JD002404.

Lau, K.-H., and N.-C. Lau, 1990: Observed structure and propagation characteristics of tropical summertime synoptic scale disturbances. Mon. Wea. Rev., 118, 1888-1913.

Lee, M.-I., and Coauthors, 2007: Sensitivity to horizontal resolution in the AGCM simulations of warm season diurnal cycle of precipitation over the United States and northern Mexico. J. Climate, 20, 1862-1881.

Lin, J., 2007: The double-ITCZ problem in IPCC AR4 coupled GCMs: Ocean-atmosphere feedback analysis. J. Climate, 20, 4497-4525.

— B. B. Mapes, M. Zhang, and M. Newman, 2004: Stratiform precipitation, vertical heating profiles, and the MaddenJulian oscillation. J. Atmos. Sci., 61, 296-309.

- and Coauthors, 2006: Tropical intraseasonal variability in 14 IPCC AR4 climate models. Part I: Convective signals. J. Climate, 19, 2665-2690.

Lorenz, D. J., and D. L. Hartmann, 2006: The effect of the MJO on the North American monsoon. J. Climate, 19, 333-343.

Mapes, B. E., S. Tulich, J. Lin, and P. Zuidema, 2006: The mesoscale convection life cycle: Building block or prototype for large-scale tropical waves? Dyn. Atmos. Oceans, 42, 3-29.

Mo, K. C., and H. M. H. Juang, 2003: Influence of sea surface temperature anomalies in the Gulf of California on North American monsoon rainfall. J. Geophys. Res., 108, 4112, doi:10.1029/2002JD002403.

Molinari, J., D. Knight, M. Dickinson, D. Vollaro, and S. Skubis, 1997: Potential vorticity, easterly waves, and eastern Pacific tropical cyclogenesis. Mon. Wea. Rev., 125, 2699-2708. 
— D. Dollaro, S. Skubis, and M. Dickinson, 2000: Origins and mechanisms of eastern Pacific tropical cyclogenesis: A case study. Mon. Wea. Rev., 128, 125-139.

Moorthi, S., and M. J. Suarez, 1992: Relaxed Arakawa-Schubert: A parameterization of moist convection for general circulation models. Mon. Wea. Rev., 120, 978-1002.

Nordeng, T. E., 1994: Extended versions of the convective parameterization scheme at ECMWF and their impact on the mean and transient activity of the model in the tropics. ECMWF Tech. Memo. 206, 41 pp.

Pan, D.-M., and D. A. Randall, 1998: A cumulus parameterization with a prognostic closure. Quart. J. Roy. Meteor. Soc., 124, 949-981.

Petersen, W. A., R. Cifelli, D. J. Boccippio, S. A. Rutledge, and C. Fairall, 2003: Convection and easterly wave structures observed in the eastern Pacific warm pool during EPIC-2001. $J$. Atmos. Sci., 60, 1754-1773.

Raymond, D. J., C. López-Carillo, and L. L. Cavazos, 1998: Case studies of developing east Pacific easterly waves. Quart. J. Roy. Meteor. Soc., 124, 2005-2034.

Russell, G. L., J. R. Miller, and D. Rind, 1995: A coupled atmosphere-ocean model for transient climate change studies. Atmos.-Ocean, 33, 683-730.

Serra, Y. L., and R. A. Houze Jr., 2002: Observations of variability on synoptic timescales in the east Pacific ITCZ. J. Atmos. Sci., 59, 1723-1743.

Slingo, J. M., and Coauthors, 1996: Intraseasonal oscillations in 15 atmospheric general circulation models: Results from an AMIP diagnostic subproject. Climate Dyn., 12, 325-357.

Sperber, K. R., 2004: Madden-Julian variability in NCAR CAM2.0 and CCSM2.0. Climate Dyn., 23, 259-278.

Tiedtke, M., 1989: A comprehensive mass flux scheme for cumulus parameterization in large-scale models. Mon. Wea. Rev., 117, 1779-1800.

Tokioka, T., K. Yamazaki, A. Kitoh, and T. Ose, 1988: The equatorial 30-60-day oscillation and the Arakawa-Schubert penetrative cumulus parameterization. J. Meteor. Soc. Japan, 66, 883-901.

Vera, C., and Coauthors, 2006: Toward a unified view of the American monsoon systems. J. Climate, 19, 4977-5000.

Wheeler, M., and G. N. Kiladis, 1999: Convectively coupled equatorial waves: Analysis of clouds and temperature in the wavenumber-frequency domain. J. Atmos. Sci., 56, 374-399.

Yang, Z.-L., D. Gochis, and W. J. Shuttleworth, 2001: Evaluation of the simulations of the North American monsoon in the NCAR CCM3. Geophys. Res. Lett., 28, 1211-1214.

Zehnder, J., D. M. Powell, and D. L. Ropp, 1999: The interaction of easterly waves, orography, and the intertropical convergence zone in the genesis of eastern Pacific tropical cyclones. Mon. Wea. Rev., 127, 1566-1585.

Zhang, G. J., and N. A. McFarlane, 1995: Sensitivity of climate simulations to the parameterization of cumulus convection in the Canadian Climate Centre general circulation model. Atmos.-Ocean, 33, 407-446. 